\title{
Article \\ Affecting Casein Micelles by Pulsed Electrical Field (PEF) for Inclusion of Lipophilic Organic Compounds
}

\author{
Dana Middendorf $^{1}{ }^{\circledR}$, Ute Bindrich ${ }^{1, *}$, Claudia Siemer $^{2}$, Stefan Töpfl ${ }^{2}(1)$ and Volker Heinz ${ }^{1}$ \\ 1 DIL e.V.-German Institute of Food Technologies, 49610 D-Quakenbrück, Germany; \\ d.middendorf@dil-ev.de (D.M.); v.heinz@dil-ev.de (V.H.) \\ 2 Elea GmbH, 49610 D-Quakenbrück, Germany; c.siemer@elea-technology.com (C.S.); \\ s.toepfl@elea-technology.com (S.T.) \\ * Correspondence: u.bindrich@dil-ev.de; Tel.: +49-(0)-5431-183-130
}

check for updates

Citation: Middendorf, D.; Bindrich, U.; Siemer, C.; Töpfl, S.; Heinz, V. Affecting Casein Micelles by Pulsed Electrical Field (PEF) for Inclusion of Lipophilic Organic Compounds. Appl. Sci. 2021, 11, 4611. https://doi.org/ 10.3390/app11104611

Academic Editor: Malgorzata Ziarno

Received: 13 April 2021

Accepted: 13 May 2021

Published: 18 May 2021

Publisher's Note: MDPI stays neutral with regard to jurisdictional claims in published maps and institutional affiliations.

Copyright: (c) 2021 by the authors. Licensee MDPI, Basel, Switzerland. This article is an open access article distributed under the terms and conditions of the Creative Commons Attribution (CC BY) license (https:/ / creativecommons.org/licenses/by/ $4.0 /)$.
Featured Application: The work has shown the potential for PEF-induced conditioning of casein micelles and inclusion of lipophilic substances. A potential application field is the use as a carrier for lipophilic substances in low-fat or fat-free product matrices, such as dairy products or drinks.

\begin{abstract}
The increased consumption of reduced-fat or non-fat products leads to a reduced intake of fat-soluble bioactive substances, such as fat-soluble vitamins. Due to their natural role as transport systems for hydrophobic substances, casein micelles (CM) might depict a viable system. The structure of $\mathrm{CM}$ is characterized by a lipophilic core stabilized by an electric double layer-like structure. Modification allows accessibility of the core and, therefore, the inclusion of fat-soluble bioactive substances. Well-known modifications are $\mathrm{pH}$ reduction and use of rennet enzyme. A completely new procedure to modify CM structure is offered by pulsed electrical fields (PEF). The principle behind PEF is called electroporation and affects the electric double layer of CM so that it is interrupted. In this way, lipophilic substances can be incorporated into CM. In this work, we evaluated integration of $\beta$-carotene into native $\mathrm{CM}$ by an industry-compatible process to overcome disadvantages associated with the use of Na-caseinate and avoid great technical effort, e.g., due to treatment with high hydrostatic pressure. Our research has shown that PEF can be used for disintegration of $\mathrm{CM}$ and that significant amounts of $\beta$-carotene can be incorporated in CM. Furthermore, after disintegration using $\mathrm{PEF}$, a combination of another PEF and thermal treatment was applied to restructure $\mathrm{CM}$ and trap significant amounts of $\beta$-carotene, permanently, ending up with an encapsulation efficiency of $78 \%$.
\end{abstract}

Keywords: casein micelle; transport system; pulsed electric field (PEF); electroporation; fat-soluble bioactive substances

\section{Introduction}

The number of overweight and obese people has increased significantly during recent years. One key aspect to reduce overweight and obesity is to reduce energy intake [1]. Thus, the demand for low-fat products and consumption of these products has significantly increased. However, this leads to a reduced intake of fat-soluble bioactive substances (FSBS) in human nutrition, such as fat-soluble vitamins. Due to their hydrophobic characteristics, FSBS require fat for being active and for being accessible to the human body. A solution to this problem can be found by creating hydrophilic natural carrier systems for incorporation of FSBS so that the amount and accessibility of hydrophobic nutrients can be increased also in low-fat products. It is already known that milk proteins, such as casein, can bind ions (e.g., $\mathrm{Ca}^{2+}, \mathrm{Fe}^{3+}$ ) and smaller, mainly hydrophobic molecules [2]. Binding of molecules occurs through several mechanisms, but mainly through hydrophobic interactions such as van der Waals attraction and hydrogen bonds [2]. Therefore, milk proteins can be regarded 
as suitable carriers of FSBS [2,3]. In this study, the possibility of using casein micelles (CM) as suitable carriers was investigated.

Native CM can be obtained by the membrane separation process of skimmed milk $[4,5]$ and are available as an industrially manufactured product. Additionally, production of artificial CM has been known and established for a long time [6,7]. Semo et al., 2007, were able to show that artificial CM effectively stabilized the lipophilic vitamin D2 in the aqueous phase. Another observed effect was the protection of vitamin D2 from light-induced degradation. In addition, digestion of artificially produced CM in the human intestinal tract was comparable to that of natural micelles. Bioavailability of $\mathrm{CM}$ loaded with vitamin $\mathrm{D}$ has been described in the literature, and it can be assumed that native $\mathrm{CM}$ will behave in the same way $[7,8]$. In addition to using artificial $\mathrm{CM}$, there were first approaches to use native CM. Menéndez-Aguirre et al., 2011, described a method for loading native CM with hydrophobic vitamin D2 by means of high-pressure treatment [9], which has been used for disintegration of micelles [10,11]. In this "dissolved" state, hydrophobic substances such as vitamins were enabled to attach themselves at single casein molecules. If pressure decreased again, micelles were reformed via non-covalent bonds between caseins. These newly organized micelles contained the FSBS, hydrophobic vitamin D2.

In another study, binding of vitamin $A$ and retinoic acid to $\alpha$ - and $\beta$-casein is reported [12]. In these investigations, the respective proteins were treated with retinol or retinoic acid in a buffer solution. The authors were able to determine the number of bound retinol molecules at $\alpha$ - and $\beta$-casein and found that $\alpha$-casein formed more stable complexes with retinol or retinoic acid than $\beta$-casein. Furthermore, binding sites on the respective protein molecules could be calculated [12].

Studies to incorporate $\beta$-carotene into $\mathrm{CM}$ have already been performed as well. Moeller et al., 2017, used native CM obtained from microfiltration of skimmed milk to identify optimal loading conditions temperatures $\left(2,20,40^{\circ} \mathrm{C}\right), \mathrm{pH}$ values $(6.8$ and 5.5$)$ and holding times $(5,15,30,60 \mathrm{~min})$. They found that $\mathrm{CM}$ were optimally primed at $2{ }^{\circ} \mathrm{C}$ and a pH of 5.5 for 5 min so that loading with $\beta$-carotene was performed under those conditions [5]. Jarunglumlert and Nakagawa, 2013, worked with spray-dried casein powders [13]. They investigated the influence of $\mathrm{pH}$ and storage time on casein aggregate structural changes, in addition to encapsulation efficiency after spray drying. Total $\beta$-carotene loading quantities were higher when a solution with lower $\mathrm{pH}$ was used for powder preparation. Furthermore, Nakagawa et al., 2014, encapsulated $\beta$-carotene by self-aggregated caseinates [14]. The $\mathrm{pH}$ of the sodium caseinate solution, which determined the degree of aggregation, tremendously affected the encapsulation yield and storage stability of $\beta$-carotene.

Caseins are amphiphilic proteins with lots of hydrophobic and hydrophilic amino-acid esters $[15,16]$. They exhibit numerous positive properties, such as biocompatibility and interfacial activity, they are non-toxic, exhibit a certain stability against temperature and the possibility to form complexes together with other molecules, as well as protective properties for sensitive loads [17]. About $95 \%$ of milk casein is suspended in the form of $\mathrm{CM}$, which are of approx. $150 \mathrm{~nm}$ in diameter. $\mathrm{CM}$ are molecular complexes consisting of different molecules ( $\alpha s^{-}, \beta-, k$ - and $\gamma$-caseins). Spatial structure of $\mathrm{CM}$ is determined by properties of casein fractions (e.g., solubility, sensitivity against calcium). A schematic diagram is depicted in Figure 1. The inner core of the micelle mainly consists of more hydrophobic caseins ( $\alpha \mathrm{s}^{-}, \beta$ - casein) forming complex structures by using calcium citrate and phosphate bridges with carboxylic groups and phosphoric acid esters of the proteins. More hydrophilic caseinomacropeptides, which are part of $k$-casein, form a hydration shell around the CM's core and reach into the aqueous phase acting as protective colloid for the $\mathrm{CM}$. The thickness of this hydration shell depends on $\mathrm{pH}$ and ion concentration. Furthermore, an electric double layer is formed at the surface of the $\mathrm{CM}$, which is responsible for the stability of CM. Hence, the electric double layer and hydrophilic shell have to be opened or disintegrated in order to incorporate FSBS into CM followed by a subsequent closing or restructuring procedure of $\mathrm{CM}$. 


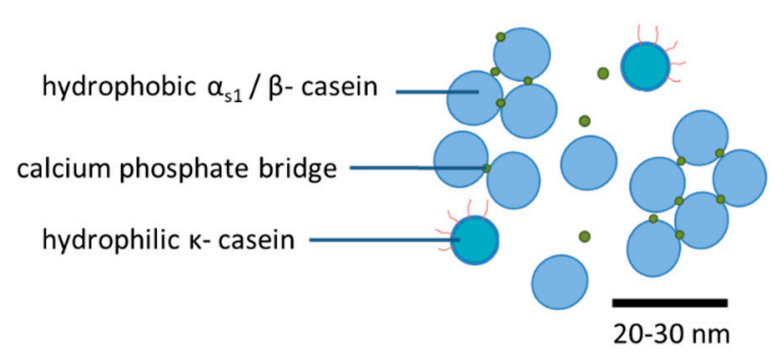

(a)

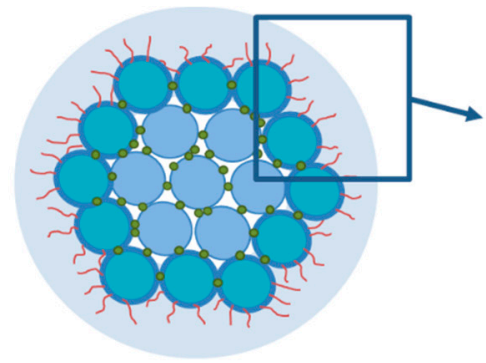

(b)

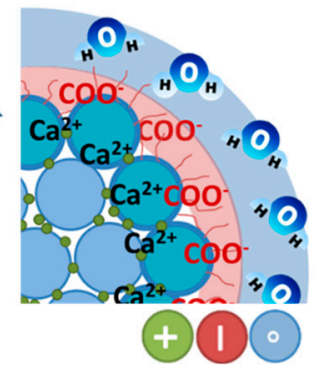

(c)

Figure 1. Schematic diagram of casein submicelles (a) forming a whole casein micelle (b). When suspended in water, an electric bilayer is formed at the CM surface (c) (for detailed description see text).

$\mathrm{CM}$ are not thermally stable. It has been observed that native $\mathrm{CM}$ free of whey protein attachments are larger due to thermal changes in casein fractions by ultra-high temperature treatment [4]. Even when cooling down to $2-6^{\circ} \mathrm{C}$, numerous physico-chemical changes take place, already investigated quite intensively in the 1970s $[18,19]$; when milk is refrigerated, a disintegration of the $\mathrm{CM}$ due to the release of the strongly hydrophobic $\beta$-caseins takes place. This disintegration can be reversed by so-called thermization at $65^{\circ} \mathrm{C}$. This means that the original properties of the $\mathrm{CM}$ are almost completely restored. When $\mathrm{pH}$ is lowered, e.g., by adding acid, colloidal calcium phosphate is solubilized, which is intended to bind the casein submicelles together [19]. This can at least lead to a loosening of the CM's substructure. If $\mathrm{pH}$ is reduced below 5.2, electrostatic attraction of $\mathrm{CM}$ increases and, therefore, intermolecular cohesion. At $\mathrm{pH} 4.6$, caseins precipitate. In principle, acid precipitation is reversible. If $\mathrm{pH}$ rises above 5.3, $\mathrm{CM}$ are held together due to colloidal calcium phosphate [19]. As a result, the structure of CM can consequently be influenced, e.g., by varying temperature and $\mathrm{pH}$.

Besides these known methods to disintegrate $\mathrm{CM}$, a new promising process can be the application of pulsed electric fields (PEF). The technology of PEF is known for the treatment of various food products to affect biological and microbial cells. During this treatment, the product is exposed to high-voltage electrical pulses between two electrodes. The electrical pulses cause the cell to polarize, which induces pore formation in the cell membrane of biological tissue $[20,21]$. The working principle is called electroporation. The process is already established in, e.g., the potato industry, to improve chips or French fries processing [21]. Further areas of application of PEF technology are the preservation of fresh juices [22].

The principle of electroporation is based on the effect of the electrical current on a cell. Each cell is surrounded by a protective membrane, which is usually composed of phospholipids and thus represents an insulator. If the cell is exposed to the high-voltage pulses, ions migrate within the cell, which causes the cell to polarize. This polarization leads to an accumulation of charge, in which the ions collect at the membrane and thus exert a kind of compression. Above a certain high voltage, the membrane can no longer withstand this pressure and a pore is formed (cf. Figure 2). Through this pore, internal components can penetrate through the previously protective layer and result in different effects, such as an inactivation of microorganisms or an increased extraction yield of valuable ingredients from fruits $[23,24]$. Important process factors that describe the intensity of the PEF treatment are electric field strength, specific energy input, pulse width and the so-called input temperature, which is the temperature of the product prior to PEF treatment [24].

As just described, the place of action of the PEF treatment is the permeable membrane, which is an electric double layer. Casein micelles also have a similar structure in the broadest sense (cf. Figure 1). Here, too, there is a charged cell that consists of a double layer that acts like an insulator. Therefore, there is a possibility that PEF can also affect the structure of casein micelles. 


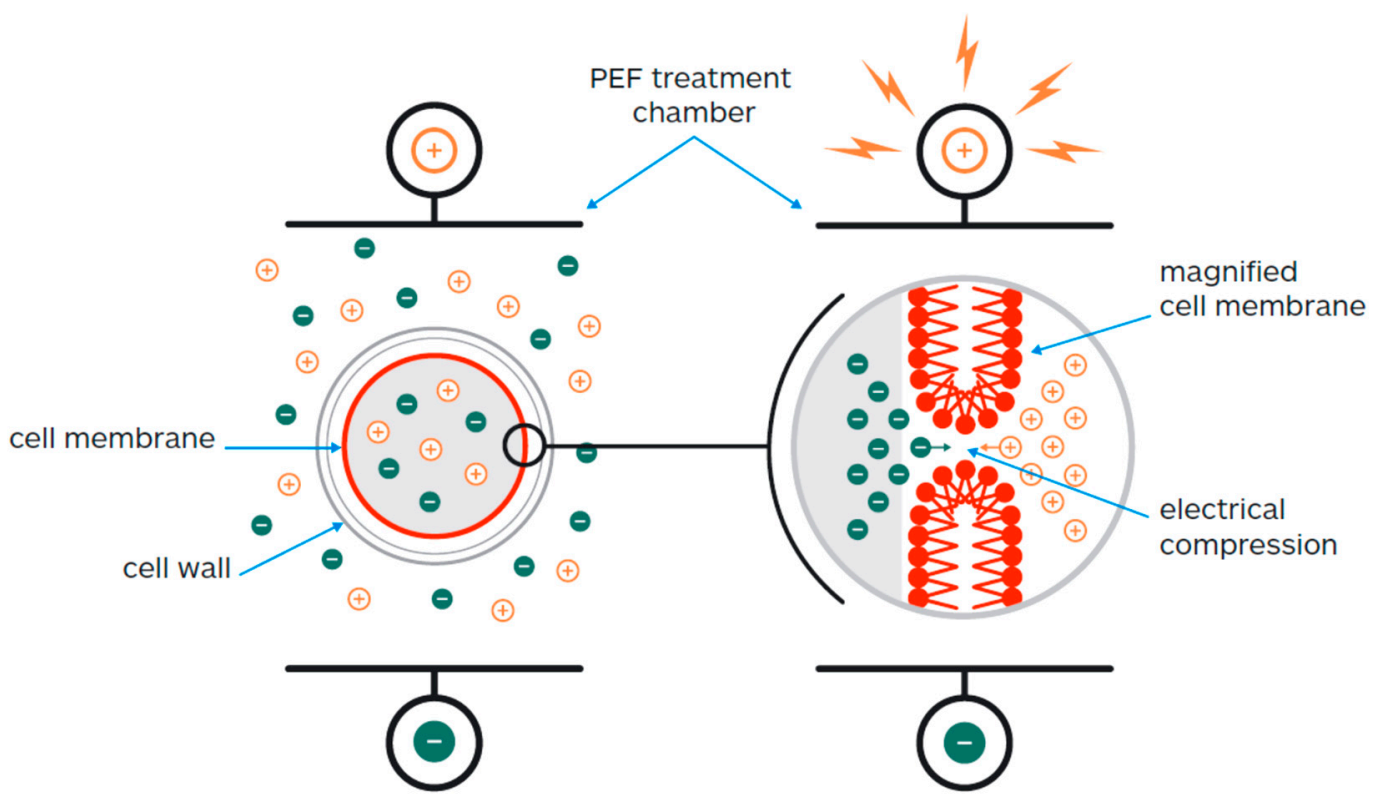

Figure 2. Schematic diagram describing the phenomenon of electroporation in biological tissue using PEF.

Up to now, only little is known about the influence of PEF application on the properties of native CM. Although treatment of milk with PEF is the subject of some scientific investigations, these aim primarily at improving the microbiological condition, as well as enzyme inactivation, and thus extension of shelf life, with focus on the preservation of vitamins and heat-sensitive proteins [25-35].

However, changes in physico-chemical and/or techno-functional aspects are also reported, and these changes are not sufficiently traced back to changes in the material state of milk ingredients. Furthermore, detected effects are not consistent. While Floury et al. [29] found a decrease in viscosity and an increase in protein coagulation, Bolshov and Kuritsyn, 2001, reported that the influence of PEF on rennet coagulation of milk resulted in a decrease in gel strength and an increase in coagulation time [34]. This suggests that $\mathrm{CM}$ were partially disintegrated by PEF, which is comparable to the effects of cooling milk $[17,18]$. However, Dunn found that PEF treatment did not induce significant changes in rennet coagulation properties [35].

Although there is not yet any scientific evidence that the use of PEF can specifically change the structural properties of $\mathrm{CM}$, there are several indications that this is possible and likely. Hence, the aim of this work was to use PEF technology in order to disintegrate CM for loading with FSBS and the subsequent restructuring of micellar structure. In this study, we used hydrophobic $\beta$-carotene, which is provitamin A, as an example for FSBS. For this, necessary PEF parameters affecting the CM have to be identified, and the respective effect on $\beta$-carotene load of casein micelles has to be monitored.

\section{Materials and Methods}

\subsection{Materials}

\subsubsection{Casein Micelle Suspension}

Casein Micelle Retentate (CMR) was kindly provided by the Institute for Safety and Quality in Milk and Fish, Max Rubner-Institute, Kiel, Germany. CMR was obtained from microfiltration of skimmed milk, which was carried out on a pilot plant system (MFS-1, TetraPak, Reinbek, Germany) with internal circuits on the permeate and retentate side. The system contained a single layer of $\mathrm{ZrO}_{2}$-ceramic module with an exchange area of $0.2 \mathrm{~m}^{2}$ and an average pore size of $0.1 \mu \mathrm{m}$ (Membralox P19-40, SCT, Bazet, France). Skimmed milk was microfiltered at $55{ }^{\circ} \mathrm{C}$ until three quarters of the amount used had passed into the permeate (concentration level 4). Permeate flow rate was set to $12.5 \mathrm{~kg} / \mathrm{h}$. Retentate 
was washed three times by diafiltration with demineralized water before it was withdrawn from the pilot plant. Prior to loading, CMR was diluted with distilled water to a target protein content of $3.5 \%$. Physical properties of CMR had to be standardized in terms of conductivity $(1.0 \mathrm{mS} / \mathrm{cm}$ using $\mathrm{NaCl})$ prior to execution of experiments.

MCC 80, an industrial semi-finished CM product (Müller Service GmbH, FreisingWeihenstephan, Germany) was used after rehydration as a CM suspension.

\subsection{2. $\beta$-Carotene Solution}

$\beta$-carotene solution was prepared using $1.2 \mathrm{mg} \beta$-carotene (Sigma-Aldrich, Type I; C9750 bzw. 22040-1G-F) dissolved in $100 \mathrm{~mL}$ ethanol (magnetic stirrer for $15 \mathrm{~min}$, and $30 \mathrm{~s}$ ultrasound).

\subsection{Methods}

\subsubsection{PEF Treatment}

The PEF treatment was conducted using a continuous operating PEF system HVP 5 (Elea Vertriebs- und Vermarktungsgesellschaft $\mathrm{mbH}$, Quakebrueck, Germany). The freshly prepared suspension was pumped through a heat exchanger to achieve a constant inlet temperature of $10^{\circ} \mathrm{C}$ of the product. Afterwards, the product was pumped through the PEF system, where it was treated with different intensities. After PEF treatment, samples were stored on ice before further analysis.

All trials were performed at a constant flow rate of $27 \mathrm{~L} / \mathrm{h}$. Rectangular, bipolar pulses were applied within two colinear treatment chambers to the product at different pulse widths starting from 15 to $25 \mu$ s. Additionally, the specific energy and electric field strength were studied in the range of 20 to $100 \mathrm{~kJ} / \mathrm{kg}$ and 10 to $20 \mathrm{kV} / \mathrm{cm}$, respectively.

\subsubsection{Analysis of $\beta$-Carotene Content}

For each sample, $8 \times 1 \mathrm{~mL}$ was weighed into Eppendorf cups and centrifuged for $1 \mathrm{~h}\left(18{ }^{\circ} \mathrm{C}, 16.060 \times \mathrm{g}\right)$. Supernatants were collected and used directly for the extraction procedure. Sediments were re-suspended using $1 \mathrm{~mL}$ EDTA solution ( $\mathrm{c}=0.1 \mathrm{~mol} / \mathrm{L}$ ) and stored at $7{ }^{\circ} \mathrm{C}$ for $12 \mathrm{~h}$ prior to extraction [5].

Quantification of $\beta$-carotene content in sediments and supernatants was performed photometrically at $\mathrm{k}=453 \mathrm{~nm}$ against $\mathrm{n}$-hexane/ethanol (98/2) serving as a blank. The amount of $\beta$-carotene was calculated according to

$$
[\mathrm{c}] \beta-\text { carotene }=\frac{\Delta \mathrm{A} \times 10,000}{2596}
$$

where $\Delta \mathrm{A}=$ Absorbance $_{\text {Sample }}-$ Absorbance $_{\text {Blank, }}$, and 2596 is the specific absorbance of $\beta$-carotene in $n$-hexane [5]. Recovery rates and loading efficiencies were calculated according to [36].

2.2.3. Determination of Particle Size Distribution (PSD) and Resulting Specific Surface Area (SSA)

Particle size distribution (PSD) was determined using a laser diffraction spectrometer (Mastersizer, 2000; with dispersion unit Hydro, 2000S, Malvern Instruments Ltd., Worcestershire, UK) according to ISO 13320-1. Volume distribution was calculated using a Mie model ([37]; used refractive index 1.51), SSA was calculated from PSD and particle density using the manufacturer-provided software.

For detailed description of effects, change in SSA (cf. $\triangle$ SSA in Figure 4) of particle fractions in each size class was evaluated. Negative values imply that the SSA of particles in the respective class is reduced compared to reference value. Positive values imply that the respective SSA of particle fraction is increased. 


\subsubsection{Determination of Surface Charge and Charge Density: Surface Potential}

Surface charge was measured using a Charge Analyzing System (CAS, emtec Electronic GmbH. Leipzig, Germany). Titrants were $0.001 \mathrm{~N}$ natriumpolyvinylstyrol (NatriumPVS) for cationic and $0.001 \mathrm{~N}$ polynatriumdiallyldimethylammoniumchloride (NatriumPoly-DADMAC) for anionic interactions, respectively. Surface charge density can be calculated via titrant volume in correlation with the amount of substance present in the system or, in the case of particles or drops in correlation, with the specific surface area.

\subsubsection{Confocal Laser Scanning Microscopy (CLSM)}

CM suspension was stained with a solution of Rhodamin B (Sigma-Aldrich, Darmstadt, Germany) in distilled water, which absorbs at $570 \mathrm{~nm}$ and emits red light of $590 \mathrm{~nm}$ wavelength. For CLSM, a Nikon Eclipse E 600 was used (NIKON Metrology GmbH, Alzenau, Germany).

\section{Results and Discussion}

\subsection{Disintegration of CM: Defining PEF Parameters}

As already described, there are reasonable assumptions that PEF application can change properties of $\mathrm{CM}$ to disintegrate the structure and, therefore, prepare them for being loaded with $\beta$-carotene. These assumptions are based on the fact that $\mathrm{CM}$ are stabilized from the outside by an electrical double layer and from the inside by calcium phosphate clusters, which causes a natural polarization of the CM (cf. Figure 1). The electric double layer includes a layer of carboxyl groups of caseinomacropeptide and a relatively mobile layer of calcium ions [38]. If the negative charge is reduced by changing the external conditions, such as an electric field, conditions comparable to the isoelectric state are created, leading to a coagulation of the micelles. This is in agreement with Lui [39], who found that the size of $\mathrm{CM}$ at $\mathrm{pH} 8$ can be influenced by PEF. Additionally, changes in charge distribution in the electric double layer can be caused by electrical pulses [40]. Hence, different PEF treatment conditions should lead to disintegration and restructuring of CM. The possible effect of PEF on CM can be studied by comparing the results of the $\mathrm{CM}$ analysis before and after the treatment. Figure 3 shows a schematic diagram of $\mathrm{CM}$ structure in native (a) and in disintegrated state (b). As can be estimated from these structures, relevant parameters for identifying the respective CM state are specific surface area (SSA), charge and charge density, as well as the surface potential.

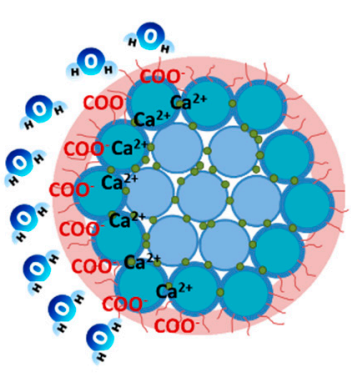

(a)

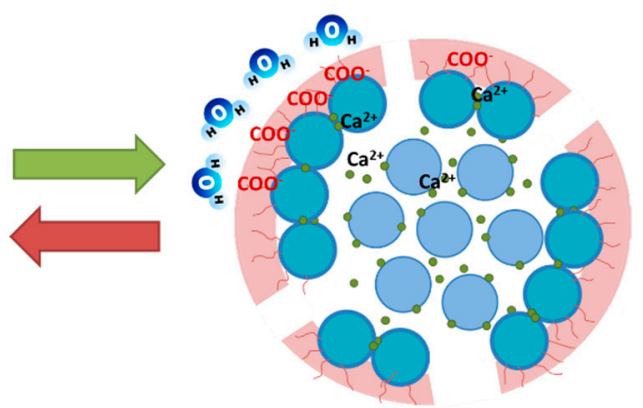

(b)

Figure 3. Schematic diagram of potential CM structure in native (a) and in disintegrated state (b).

Properties pointing to CM disintegration are larger SSA due to volume changes and higher charge density. A higher charge density results from charge carriers being more available (e.g., for the titrants used for determination). Furthermore, surface potential is also relevant as a lower negative value is found for treated $\mathrm{CM}$ compared to native (untreated) CM (data not shown). Hence, PEF parameters for CM disintegration have to be identified so that CM properties are adapted in the way of a higher SSA and charge density, as well as a lower negative surface potential. 
Previous studies (data not shown) have shown that the biggest differences in the effect of disintegration were found at different electric field strengths and pulse widths. Only a limited effect on CM disintegration was detected for specific energy intake. Therefore, the lowest energy level was used for further investigations in order to allow a higher capacity for industrial application, and also lower energy costs. The results concerning SSA are summarized in Figure 4 and correlated with CLSM images. Here, the difference in SSA before and after PEF treatment $(\triangle S S A)$ is correlated with electric field strength and pulse width. Since CMR's isolation is very complex and cost-intensive, only limited amounts were available, so the industrial semi-finished product MCC 80 was used for these basic preliminary tests.

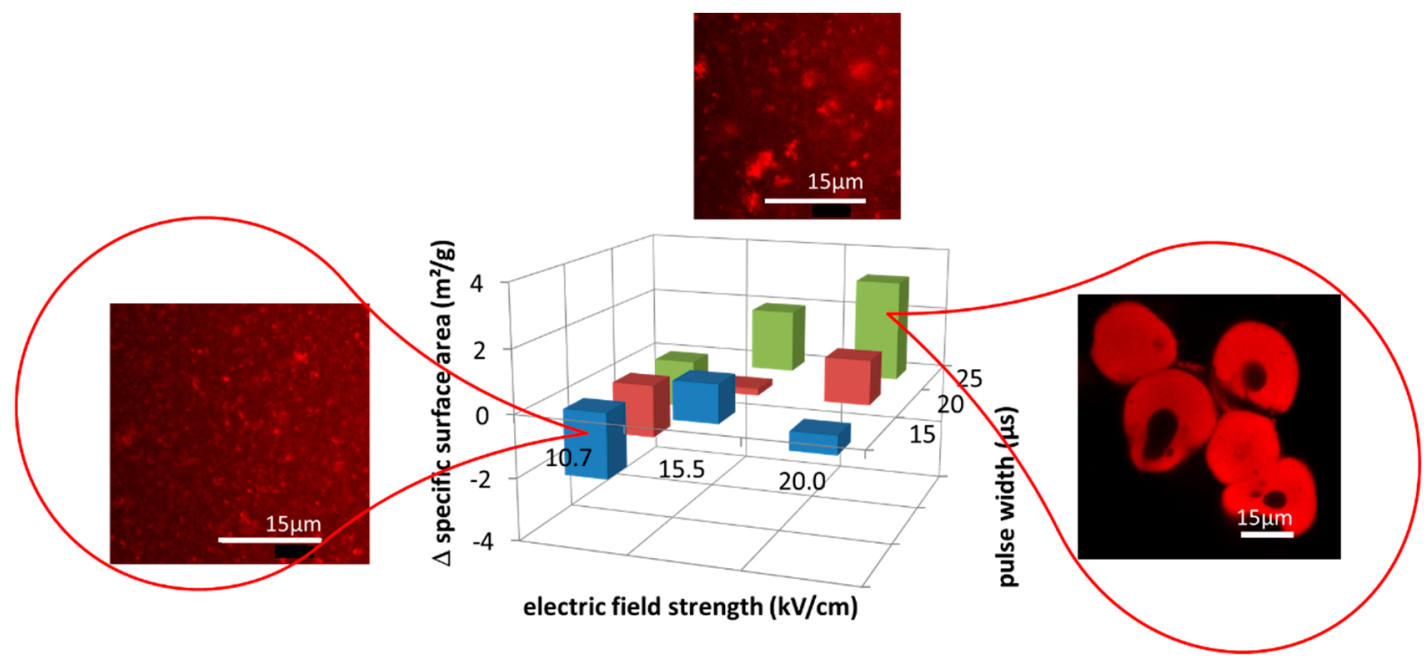

Figure 4. Effect of PEF on SSA of rehydrated CM at different electric field strengths $(10.7-20 \mathrm{kV} / \mathrm{cm})$ and pulse width (15-25 $\mu \mathrm{s})$, applying a specific energy of $25 \mathrm{~kJ} / \mathrm{kg}$ and an inlet temperature of $10^{\circ} \mathrm{C}, \triangle \mathrm{SSA}=\mathrm{SSA}$ before PEF $-\mathrm{SSA}$ after PEF.

The application of low electric field strength and short pulse widths result in the most negative difference, meaning an increase in SSA, which is correlated with the disintegration of agglomerates/CM. High electric field strength and long pulse width lead to the most positive difference, which is correlated with a decrease in SSA and the formation of agglomerates/CM, respectively. These aspects are verified and visualized using CLSM. As a control sample, a CLSM image of rehydrated, spray-dried CM is also shown for comparison.

PEF also modifies the charge density of CM (cf. Figure 5). As already described, an increase in charge density means that the availability of free charge carriers has also increased, which implies disintegration of CM. Consequently, a decrease in charge density stands for a decrease in the availability of free charge carriers, implying an agglomeration, respectively. The results after PEF treatment are summarized in Figure 5. The highest charge density was found for low electric field strength and short pulse width, whereas the lowest charge density was found for high electric field strength and long pulse width. Other medium PEF parameters result in partially comparable values for charge density.

Considering also the results of SSA and charge density, the favorable PEF parameters for $\mathrm{CM}$ disintegration can be defined as follows: $\mathrm{E}=10.7 \mathrm{kV} / \mathrm{cm}$, pulse width $=15 \mu$ s, inlet temperature of $10^{\circ} \mathrm{C}, \mathrm{W}=25 \mathrm{~kJ} / \mathrm{kg}$. 


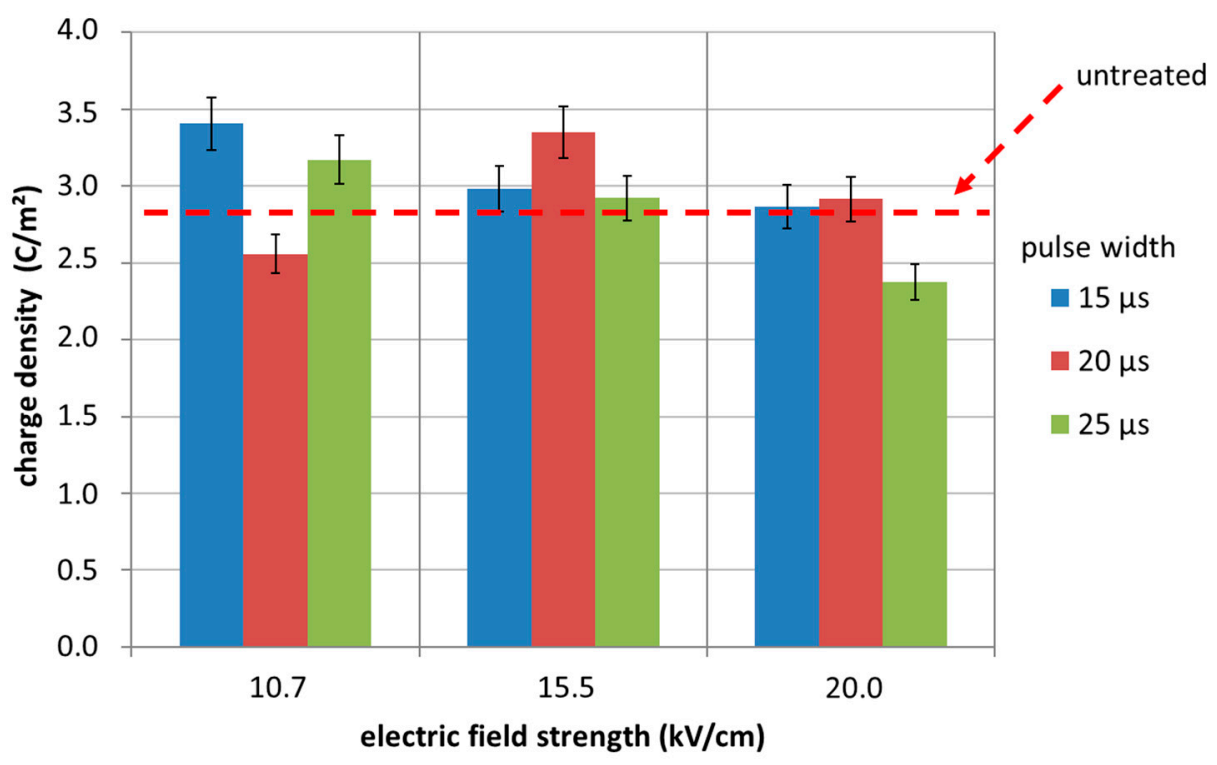

Figure 5. Modification of charge density of $\mathrm{CM}$ after PEF application with different pulse widths $(15-25 \mu \mathrm{s})$ and electric field strengths $(10.7-20 \mathrm{kV} / \mathrm{cm})$, applying a specific energy of $25 \mathrm{~kJ} / \mathrm{kg}$ and an inlet temperature of $10^{\circ} \mathrm{C}$, compared to the values of an untreated CM sample (dashed line).

\subsection{Loading Procedure and Restructuring of CM by Thermization}

For loading of disintegrated CM (PEF1 treated), $6 \mathrm{~mL}$ of $\beta$-carotene solution $(\mathrm{c}=1.2 \mathrm{mg} / 100 \mathrm{~mL}$ ) were added dropwise to $100 \mathrm{~mL} \mathrm{CM}$ retentate using a magnetic stirrer for $60 \mathrm{~min}$. Loading procedure was performed in a darkened room under red light. After different incubation times at $60^{\circ} \mathrm{C}\left(\mathrm{t}_{\text {therm }}=0,15,30,45 \mathrm{~min}\right)$ for restructuring of $\mathrm{CM}$ (thermization), loading effectiveness was monitored by analyzing the $\beta$-carotene content (cf. 0 ) and surface potential of CM (cf. 0). As a control, CM suspension was pumped through the PEF unit, but no PEF treatment was applied (no disintegration). CM remain closed and it can be expected that no $\beta$-carotene was incorporated (cf. Figure 6a). For other samples, PEF parameters as determined for disintegration were applied (PEF1, see also Section 3). The corresponding state of $\mathrm{CM}$ is depicted in Figure $6 \mathrm{~b}$. The results in terms of surface potential and $\beta$-carotene content are summarized in Table 1.

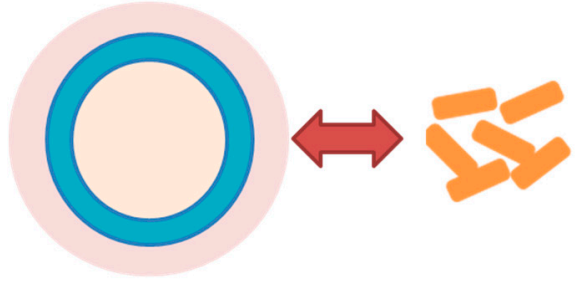

(a)

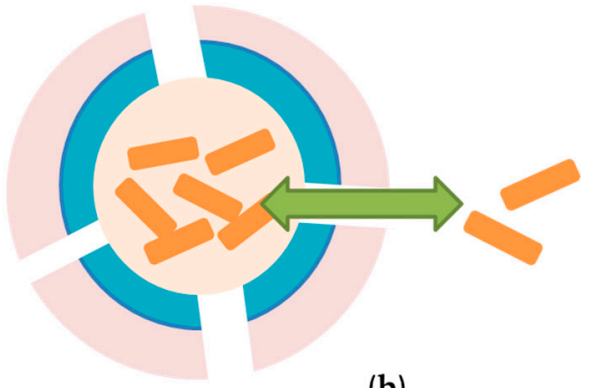

(b)

Figure 6. Schematic diagram of CM state before (a) and after PEF treatment (b), as well as respective interaction with $\beta$-carotene molecules. 
Table 1. Surface potential and $\beta$-carotene content of $\mathrm{CM}$ after different incubation times at $60{ }^{\circ} \mathrm{C}\left(\mathrm{t}_{\text {therm }}\right)$ with and without PEF1 treatment (control).

\begin{tabular}{cccccc}
\hline & Control & \multicolumn{3}{c}{ PEF1-Treated } \\
$\mathbf{t}_{\text {therm }}$ & $\mathbf{1 5}$ & $\mathbf{0}$ & $\mathbf{1 5}$ & $\mathbf{3 0}$ & $\mathbf{4 5}$ \\
\hline surface potential $(\mathrm{mV})$ & $-663 \pm 28$ & $-638 \pm 26$ & $-565 \pm 29$ & $-473 \pm 29$ & $-407 \pm 31$ \\
$\beta$-carotene content $(\mu \mathrm{g} / \mathrm{100 \textrm {g } )}$ & $<5$ & $<5$ & $-22 \pm 5$ & $-0.24 \pm 6$ & $-51 \pm 5$ \\
\hline
\end{tabular}

As expected, the surface potential of the PEF1-untreated control sample after $15 \mathrm{~min}$ thermization was most negative compared to PEF1-treated samples with incubation times $\geq 15 \mathrm{~min}$. The most negative surface potential implies that almost no disintegration took place and the $\mathrm{CM}$ were still closed. The negative value can be explained by carboxylate ions at the CM surface, which are densely arranged. As a result, no $\beta$-carotene could be incorporated into CM. Additionally, no $\beta$-carotene was found for the PEF1-treated sample without thermization ( $0 \mathrm{~min}$ ). In this case, $\mathrm{CM}$ were disintegrated through PEF1, but due to the missing thermization procedure, $\mathrm{CM}$ were not rearranged or closed for incorporation of $\beta$-carotene molecules (Figure 6a). A slightly less negative surface potential and no $\beta$-carotene was found.

However, the longer thermization after PEF1 is carried out, the less negative the surface potential is (cf. Table 1). One the one hand, this can be explained by the thermal activity of $\mathrm{CM}$ or motion of ions in $\mathrm{CM}$, e.g., $\mathrm{Ca}^{2+}$ ions, which are more present at the $\mathrm{CM}$ surface. On the other hand, diffusion of $\beta$-carotene molecules in not-completely disintegrated $\mathrm{CM}$ can also influence surface potential, leading to less negative values, as well. The maximum of $\beta$-carotene content in CM was found after PEF1 treatment and an incubation time of $30 \mathrm{~min}$. In contrast, the incorporated amount of $\beta$-carotene was less after $45 \mathrm{~min}$ of incubation. As $\mathrm{CM}$ were treated with a higher temperature over a longer period of time, reorganization of $\mathrm{CM}$ is affected in a negative way and diffusion of $\beta$-carotene is possible (Figure $6 \mathrm{~b}$ ) so that a lesser amount of $\beta$-carotene molecules was found.

As a result, PEF1 treatment can be regarded as necessary for the disintegration of $\mathrm{CM}$, and only in combination with subsequent thermal treatment, can incorporation of $\beta$-carotene into $\mathrm{CM}$ be realized.

\subsection{Restructuring of CM via PEF}

However, the process described above results in comparably low and unsatisfactory $\beta$-carotene contents in CM. In order to enhance the amount of incorporated $\beta$-carotene, another PEF treatment (PEF2) for closing or restructuring of CM was tested. Extensive trials have shown that another PEF treatment alone is not sufficient for incorporation with significant amounts of $\beta$-carotene and closing of $\mathrm{CM}$ (data not shown). Hence, a combination of PEF2 and thermization was tested to restructure CM and increase $\beta$ carotene load. For this, suitable PEF2 parameters have to be identified first, and it was found that higher PEF intensities were required. The reason for this is explained by the PEF effect on cells. At higher intensities and also higher product temperatures, the structure of $\mathrm{CM}$ is more influenced by PEF with regard to disintegration and a related CM reorientation. Higher temperatures and intensities may lead to a higher degree of interruptions, resulting in higher destabilization of $\mathrm{CM}$ at the beginning. However, after the treatment and due to the composition of $\mathrm{CM}$, a reorientation and an agglomeration occurs. Within the first trials (data not shown), it was observed that the energy level had a greater influence on the agglomeration of $\mathrm{CM}$ than the electric field strength. Therefore, the electric field strength was kept constant at $15 \mathrm{kV} / \mathrm{cm}$ and specific energy and inlet temperature were varied. In combination with different thermization times, PEF2 parameters and $\beta$-carotene content are shown in Figure 7. 


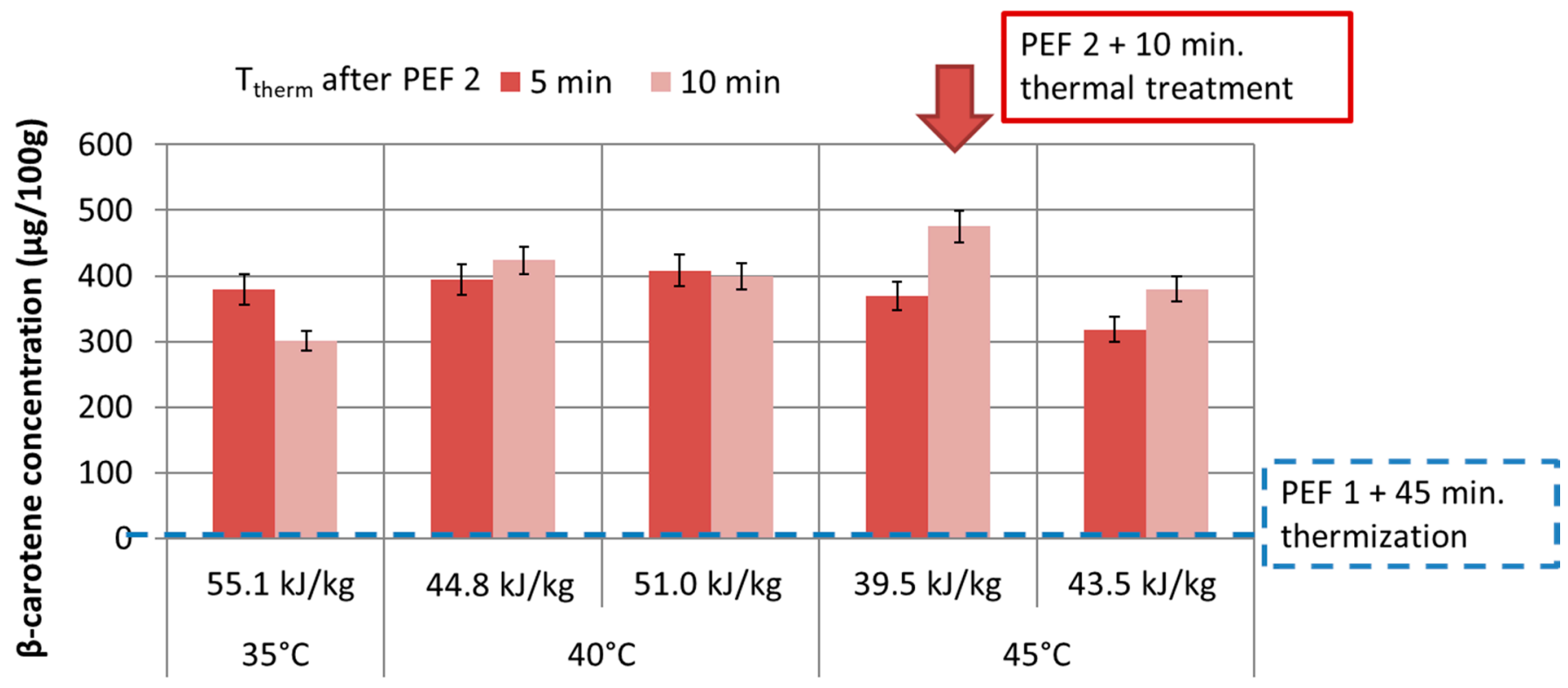

specific energy $(\mathrm{kJ} / \mathrm{kg}) /$ inlet temperature $\left({ }^{\circ} \mathrm{C}\right), \mathrm{E}=15 \mathrm{KV} / \mathrm{cm}$

Figure 7. $\beta$-carotene content in PEF-assisted thermization (PEF 2) of CM after being previously disintegrated by PEF (PEF1).

It was found that a combination of PEF2 treatment and incubation time at $60^{\circ} \mathrm{C}$ lead to significantly higher amounts of incorporated $\beta$-carotene and shorter incubation times compared to the application of PEF1 and thermization alone; thermal treatment could be decreased to 5 or $10 \mathrm{~min}$ and $\beta$-carotene content could be increased by at least 10 times (see dashed line in Figure 7 representing $\beta$-carotene content after PEF1 and thermization for $45 \mathrm{~min}$ ). Thus, a maximum $\beta$-carotene in $\mathrm{CM}$ of $475 \mu \mathrm{g} / 100 \mathrm{~g}$ was found for the application of PEF2 $\left(\mathrm{E}=15 \mathrm{kV} / \mathrm{cm}, \mathrm{W}=39.5 \mathrm{~kJ} / \mathrm{kg}\right.$, Tin $=45^{\circ} \mathrm{C}$, pulse width $\left.=15 \mu \mathrm{s}\right)$ and subsequent thermal treatment for $10 \mathrm{~min}$. The recovery rate for this procedure is $78 \%$. In comparison, the recovery rate for disintegration via PEF1 followed by a thermization process of $45 \mathrm{~min}$ (cf. Table 1) is only $22 \%$.

As already described in the introduction, other studies to incorporate $\beta$-carotene into CM have already been performed. For this, Moeller et al., 2017, used native CM and found recovery rates of $79 \%$, whereby $94 \%$ of it was associated with the native CM $[5,36]$. Jarunglumlert and Nakagawa, 2013, obtained recovery rates of up to 35\% $\beta$-carotene using spray-dried casein powders [13]. Other studies used caseinate and a self-assembling procedure to incorporate $\beta$-carotene; Nakagawa et al., 2014, obtained up to a $62 \%$ recovery rate [14] and Saiz-Abajo et al., 2013, determined a total extraction yield of $60 \%$ [41]. Compared to the results of these laboratory studies, recovery rates for the technical-scale PEF encapsulation technique presented in our study are comparably high.

\section{Conclusions}

We found in our study that PEF treatment is a suitable tool to prepare the structure of $\mathrm{CM}$ in such a way that lipophilic organic compounds, such as $\beta$-carotene, can be introduced (disintegration). As only small amounts of $\beta$-carotene were found in $C M$ after restructuring by a classical thermization procedure for closing/restructuring of CM, another PEF treatment procedure in combination with thermization was successfully implemented to increase $\beta$-carotene content in CM. Consequently, this combination led to $\beta$-carotene contents which were 10 times higher compared to classical thermization processes, corresponding to a recovery rate of $78 \%$. As a summary, PEF is a suitable process to disintegrate CM for the inclusion of fat-soluble bioactive substances and also for restructuring the $\mathrm{CM}$ after the inclusion.

However, knowledge on the detailed mechanism of action during PEF treatment, especially on CM, is still very limited. Additionally, interactions of CM with other FSBS in 
combination with PEF treatment for incorporation/restructuring have not been investigated in detail, so far. Further studies are required to fully understand the effect of PEF on $\mathrm{CM}$ and the related possibility for inclusion of fat-soluble bioactive substances.

\section{Patents}

The following patents are pending: USA $(16 / 638,423)$, Canada $(3,072,850)$, Europe (18756408.3) and Germany (102017214305.3).

Author Contributions: Conceptualization, U.B. and S.T.; Data curation, U.B.; Formal analysis, D.M., U.B. and C.S.; Funding acquisition, U.B., S.T. and V.H.; Investigation, D.M., U.B. and C.S.; Methodology, D.M., U.B. and C.S.; Project administration, U.B., S.T. and V.H.; Resources, D.M., S.T. and V.H.; Supervision, U.B. and S.T.; Validation, D.M., U.B. and C.S.; Visualization, D.M. and C.S.; Writing—original draft, D.M. and U.B.; Writing—review and editing, D.M., U.B., C.S., S.T. and V.H. All authors have read and agreed to the published version of the manuscript.

Funding: This IGF Project of the FEI was supported via AiF within the program for promoting the Industrial Collective Research (IGF) of the German Ministry of Economic Affairs and Energy (BMWi), based on a resolution of the German Parliament.

Institutional Review Board Statement: Not applicable.

Informed Consent Statement: Not applicable.

Acknowledgments: We would like to thank the Institute for Safety and Quality in Milk and Fish, Max Rubner-Institute, Kiel, Germany for providing Casein Micelle Retentate (CMR) and Müller Service $\mathrm{GmbH}$, Freising-Weihenstephan, Germany for providing the industrial semi-finished CM product MCC 80.

Conflicts of Interest: The authors declare no conflict of interest.

\section{References}

1. World Health Organization. Obesity and Overweight. WHO Fact Sheet No. 311. 2014. Available online: http://www.who.int/ mediacentre/factsheets/fs311/en/\# (accessed on 8 April 2017).

2. Livney, Y.D. Milk proteins as vehicles for bioactives. Curr. Opin. Colloid Interface Sci. 2010, 15, 73-83. [CrossRef]

3. Keppler, J.; Schwarz, K. Milk proteins as nanotransporters. Eur. Diary Mag. 2012, 10-13.

4. Bulca, S.; Leder, J.; Kulozik, U. Impact of UHT or high heat treatment on the rennet gel formation of skim milk with various whey protein content. Milchwissenschaft 2004, 59, 590-593.

5. Moeller, H.; Martin, D.; Schrader, K.; Hoffmann, W.; Lorenzen, P.C. Native casein micelles as nanocarriers for $\beta$-carotene: $\mathrm{pH}$-and temperature-induced opening of the micellar structure. Int. J. Food Sci. Technol. 2017, 52, 1122-1130. [CrossRef]

6. Knoop, A.-M.; Knoop, E.; Wiechen, A. Sub-structure of synthetic casein micelles. J. Dairy Res. 1979, 46, 347-350. [CrossRef]

7. Semo, E.; Kesselman, E.; Danino, D.; Livney, Y. Casein micelle as a natural nano-capsular vehicle for nutraceuticals. Food Hydrocoll. 2007, 21, 936-942. [CrossRef]

8. Haham, M.; Ish-Shalom, S.; Nodelman, M.; Duek, I.; Segal, E.; Kustanovich, M.; Livney, Y.D. Stability and bioavailability of vitamin D nanoencapsulated in casein micelles. Food Funct. 2012, 3, 737-744. [CrossRef] [PubMed]

9. Menéndez-Aguirre, O.; Stuetz, W.; Grune, T.; Kessler, A.; Weiss, J.; Hinrichs, J. High pressure-assisted encapsulation of vitamin $\mathrm{D}_{2}$ in reassembled casein micelles. High Press. Res. 2011, 31, 265-274. [CrossRef]

10. Schrader, K.; Morr, C.; Buchheim, W. High pressure effects on the colloidal calcium phosphate and the structural integrity of micellar casein in milk. Prog. Biotechnol. 1996, 13, 347-350.

11. Huppertz, T.; Fox, P.F.; Kelly, A.L. Dissociation of caseins in high pressure-treated bovine milk. Int. Dairy J. 2004, 14, 675-680. [CrossRef]

12. Bourassa, P.; N'Soukpoé-Kossi, C.; Tajmir-Riahi, H. Binding of vitamin A with milk $\alpha$ - and $\beta$-caseins. Food Chem. 2013, 138, 444-453. [CrossRef]

13. Jarunglumlert, T.; Nakagawa, K. Spray drying of casein aggregates loaded with $\beta$-carotene: Influences of acidic conditions and storage time on surface structure and encapsulation efficiencies. Dry Technol. 2013, 31, 1459-1465. [CrossRef]

14. Nakagawa, K.; Jarunglumlert, T.; Adachi, S. Microencapsulation of $\beta$-carotene by self-aggregated caseinates. Jpn. J. Food Eng. 2014, 15, 51-57. [CrossRef]

15. Elzoghby, A.O.; Samy, W.M.; Elgindy, N.A. Protein-based nanocarriers as promising drug and gene delivery systems. J. Control. Release 2012, 161, 38-49. [CrossRef]

16. Elzoghby, A.O.; El-Fotoh, W.S.A.; Elgindy, N.A. Casein-based formulations as promising controlled release drug delivery systems. J. Control. Release 2011, 153, 206-216. [CrossRef] 
17. Reimerdes, E.H.; Jimenezperez, S.; Ringqvist, B.M. Temperature-dependent changes in milk-products. 3. Thermization-A corrective step in processing of refrigerated milk. Milchwissenschaft 1977, 32, 207-210.

18. Reimerdes, E.H. Changes in the proteins of raw milk during storage. Dev. Dairy Chem. 1982, 1, 271-288.

19. Walstra, P. On the Stability of Casein Micelles. J. Dairy Sci. 1990, 73, 1965-1979. [CrossRef]

20. Saulis, G.; Wouters, P. Probable mechanisms of microorganism inactivation by pulsed electric fields. Food Preserv. Pulsed Electr. Fields 2007, 2007, 138-155.

21. Fauster, T.; Ostermeier, R.; Scheibelberger, R.; Jäger, H. Pulsed Electric Field (PEF) Application in the Potato Industry. Innov. Food Process. Technol. 2021, 2021, 253-270.

22. Marsellés-Fontanet, A.R.; Elez-Martínez, P.; Martín-Belloso, O. Juice preservation by pulsed electric fields. Stewart Postharvest Rev. 2012, 8, 1-4.

23. Toepfl, S.; Heinz, V. Mass Transport Improvement by PEF-Applications in the Area of Extraction and Distillation. Distill. Adv. Model. Appl. 2012, 2012, 211-232.

24. Toepfl, S.; Heinz, V.; Knorr, D. High intensity pulsed electric fields applied for food preservation. Chem. Eng. Process. Process. Intensif. 2007, 46, 537-546. [CrossRef]

25. Calderón-Miranda, M.L.; Barbosa-Cánovas, G.V.; Swanson, B.G. Inactivation of Listeria innocua in liquid whole egg by pulsed electric fields and nisin. Int. J. Food Microbiol. 1999, 51, 7-17. [CrossRef]

26. Picart, L.; Dumay, E.; Cheftel, J. Inactivation of Listeria innocua in dairy fluids by pulsed electric fields: Influence of electric parameters and food composition. Innov. Food Sci. Emerg. Technol. 2002, 3, 357-369. [CrossRef]

27. Sampedro, F.; Rodrigo, M.; Martinez, A.; Barbosa-Cánovas, G.V.; Rodrigo, D. Quality and Safety Aspects of PEF Application in Milk and Milk Products. Crit. Rev. Food Sci. Nutr. 2005, 45, 25-47. [CrossRef]

28. Sepulveda, D.; Góngora-Nieto, M.; Guerrero, J.; Barbosa-Cánovas, G. Production of extended-shelf life milk by processing pasteurized milk with pulsed electric fields. J. Food Eng. 2005, 67, 81-86. [CrossRef]

29. Floury, J.; Grosset, N.; Leconte, N.; Pasco, M.; Madec, M.-N.; Jeantet, R. Continuous raw skim milk processing by pulsed electric field at non-lethal temperature: Effect on microbial inactivation and functional properties. Le Lait 2005, 86, 43-57. [CrossRef]

30. Odriozola-Serrano, I.; Bendicho-Porta, S.; Martín-Belloso, O. Comparative Study on Shelf Life of Whole Milk Processed by High-Intensity Pulsed Electric Field or Heat Treatment. J. Dairy Sci. 2006, 89, 905-911. [CrossRef]

31. Sobrino-López, Á.; Martín-Belloso, O. Enhancing Inactivation of Staphylococcus aureus in Skim Milk by Combining High-Intensity Pulsed Electric Fields and Nisin. J. Food Prot. 2006, 69, 345-353. [CrossRef]

32. Guerrero-Beltrán, J.Á.; Sepulveda, D.R.; Góngora-Nieto, M.M.; Swanson, B.; Barbosa-Cánovas, G.V. Milk thermization by pulsed electric fields (PEF) and electrically induced heat. J. Food Eng. 2010, 100, 56-60. [CrossRef]

33. Bermúdez-Aguirre, D.; Fernández, S.; Esquivel, H.; Dunne, P.C.; Barbosa-Cánovas, G.V. Milk Processed by Pulsed Electric Fields: Evaluation of Microbial Quality, Physicochemical Characteristics, and Selected Nutrients at Different Storage Conditions. J. Food Sci. 2011, 76, S289-S299. [CrossRef] [PubMed]

34. Bolshov, M.A.; Kuritsyn, Y.A. Laser Analytical Spectroscopy. Ullmann's Encycl. Ind. Chem. 2001, $2012,595-631$.

35. Dunn, J. Pulsed Light and Pulsed Electric Field for Foods and Eggs. Poult. Sci. 1996, 75, 1133-1136. [CrossRef]

36. Moeller, H.; Martin, D.; Schrader, K.; Hoffmann, W.; Pargmann, S.; Kurz, J.; Lorenzen, P.C. Comparative studies of loading lipophilic substances into casein micelles and investigating the influence of whey proteins and heat treatment on loading stability. Int. J. Dairy Technol. 2018, 71, 954-965. [CrossRef]

37. Mie, G. Beiträge zur Optik rüber Medien, speziell kolloidaler Metallösungen. Ann. Phys. 1908, 4, 377-445. [CrossRef]

38. Kirchmei, O. Secondary Phase of Milk Coagulation by Rennin; 2. Changes in Electrochemical State of Micelle. Z. Lebensm. Unters. Forsch. 1972, 149, 211-215.

39. Liu, Z. Effects of Pulsed Electric Field Processing and Ultrasound Processing on the Physicochemical and Functional Properties of Proteins in Milk. Ph.D. Thesis, RMIT University, Melbourne, Australia, August 2012.

40. Puippe, J.C.; Ibl, N. Influence of charge and discharge of electric double layer in pulse plating. J. Appl. Electrochem. 1980, 10, 775-784. [CrossRef]

41. Saiz-Abajo, M.J.; Gonzalez-Ferrero, C.; Moreno-Ruiz, A.; Romo-Hualde, A.; Gonzalez-Navarro, C.J. Thermal protection of $\beta$-carotene in re-assembled casein micelles during different processing technologies applied in food industry. Food Chem. 2013, 138, 1581-1587. [CrossRef] 